\title{
Common Fixed Point and Coupled Coincidence Point Theorems for Geraghty's Type Contraction Mapping with Two Metrics Endowed with a Directed Graph
}

\author{
P. Charoensawan and W. Atiponrat \\ Center of Excellence in Mathematics and Applied Mathematics, Department of Mathematics, Faculty of Science, \\ Chiang Mai University, Chiang Mai 50200, Thailand
}

Correspondence should be addressed to W. Atiponrat; watchareepan.a@cmu.ac.th

Received 10 April 2017; Accepted 11 October 2017; Published 16 November 2017

Academic Editor: Nan-Jing Huang

Copyright (C) 2017 P. Charoensawan and W. Atiponrat. This is an open access article distributed under the Creative Commons Attribution License, which permits unrestricted use, distribution, and reproduction in any medium, provided the original work is properly cited.

The purpose of this paper is to present some existence and uniqueness results for common fixed point theorems for $\theta-\phi \operatorname{contraction}$ mappings with two metrics endowed with a directed graph. In addition, by using our main results, we obtain some results about coupled coincidence points endowed with a directed graph. Our results generalize those presented in previous papers.

\section{Introduction and Preliminaries}

Geraghty [1] introduced an interesting class $\Theta$ of functions $\theta:[0, \infty) \rightarrow[0,1)$ satisfying that

$$
\theta\left(t_{n}\right) \longrightarrow 1 \Longrightarrow t_{n} \longrightarrow 0
$$

and they have shown some results which are a generalization of Banach's contraction principle in 1973.

Recently, Martínez-Moreno et al. [2] gave some new common fixed point theorems for Geraghty's type contraction mappings employing the monotone property with two metrics by using $d$-compatibility and $g$-uniform continuity where the concept of $d$-compatibility is defined as follows.

Definition 1 (see [3]). Let $(X, d)$ be a metric space, and let $f, g: X \rightarrow X$ be two mappings. The mappings $g$ and $f$ are said to be $d$-compatible if

$$
\lim _{n \rightarrow \infty} d\left(g f x_{n}, f g x_{n}\right)=0
$$

whenever $\left\{x_{n}\right\}$ is a sequence in $X$ such that $\lim _{n \rightarrow \infty} f x_{n}=$ $\lim _{n \rightarrow \infty} g x_{n}$.
In [2], there are many results on multidimensional common fixed point theorems which generalize the results in paper [4].

The fixed point theorem employing the concept of metric spaces endowed with a graph was initiated by Jachymski [5], which generalizes the Banach contraction principle to mappings on metric spaces equipped with a graph. Also, the definitions of $G$-continuous and property $A$ were given in [5].

Definition 2 (see [5]). A function $f: X \rightarrow X$ is said to be $G$ continuous if and only if, for any $x \in X$ which has a sequence $\left\{x_{n}\right\}$ in $X, x_{n} \rightarrow x$, and $\left(x_{n}, x_{n+1}\right) \in E(G)$ for $n \in \mathbb{N}$, we have that $f\left(x_{n}\right) \rightarrow f(x)$.

Definition 3 (see [5]). Suppose that $(X, d)$ is a metric space and $G$ is a directed graph. The triple $(X, d, G)$ is said to have property $A$ if and only if for any sequence $\left\{x_{n}\right\}$ in $X$ such that $x_{n} \rightarrow x$ and $\left(x_{n}, x_{n+1}\right) \in E(G)$, where $n \in \mathbb{N}$, we have that $\left(x_{n}, x\right) \in E(G)$.

After the discovery above, many researchers have studied the topic of existence of a fixed point for single-valued mappings and multivalued mappings in various spaces equipped with a graph; see [6-11]. 
In the case of coupled fixed point with a graph, which will be our topic of interest, we now give a collection of notions and definitions from [12].

Definition 4 (see [12]). The given functions $F: X \times X \rightarrow X$ and $g: X \rightarrow X$ are said to be $G$-edge preserving if and only if the following condition is satisfied:

$$
\begin{aligned}
\text { If } & (g x, g u),(g y, g v) \in E(G), \\
\text { then } \quad & (F(x, y), F(u, v)),(F(y, x), F(v, u)) \\
& \in E(G) .
\end{aligned}
$$

Definition 5 (see [12]). Suppose that $(X, d)$ is a metric space and $E(G)$ is the set of all edges of the graph $G . E(G)$ is said to have the transitivity property if and only if, for all $x, y$, and $a \in X$, the following is true:

$$
\text { If }(x, a),(a, y) \in E(G), \quad \text { then }(x, y) \in E(G) \text {. }
$$

Definition 6 (see [12]). A function $F: X \times X \rightarrow X$ is said to be $G$-continuous if and only if the following are true. For any $\left(x^{*}, y^{*}\right) \in X \times X$ and any sequence $\left(n_{i}\right)_{i \in \mathbb{N}}$ of positive integers such that $\left(F\left(x_{n_{i}}, y_{n_{i}}\right), F\left(x_{n_{i}+1}\right.\right.$, $\left.\left.y_{n_{i}+1}\right)\right)$ and $\left(F\left(y_{n_{i}}, x_{n_{i}}\right), F\left(y_{n_{i}+1}, x_{n_{i}+1}\right)\right) \in E(G), F\left(x_{n_{i}}, y_{n_{i}}\right) \rightarrow$ $x^{*}$, and $F\left(y_{n_{i}}, x_{n_{i}}\right) \rightarrow y^{*}$ as $i \rightarrow \infty$, we have that as $i \rightarrow \infty$,

$$
\begin{aligned}
& F\left(F\left(x_{n_{i}}, y_{n_{i}}\right), F\left(y_{n_{i}}, x_{n_{i}}\right)\right) \longrightarrow F\left(x^{*}, y^{*}\right), \\
& F\left(F\left(y_{n_{i}}, x_{n_{i}}\right), F\left(x_{n_{i}}, y_{n_{i}}\right)\right) \longrightarrow F\left(y^{*}, x^{*}\right) .
\end{aligned}
$$

In 2015, Suantai et al. [12] used the above definitions to investigate some results on existence and uniqueness for coupled coincidence points and common fixed points of $\theta$ $\psi$ contraction mappings in complete metric spaces endowed with a directed graph. Their results also generalize others in partially ordered metric spaces.

The aim of this paper is to present some existence and uniqueness results for common fixed point theorems for $\theta$ $\phi$ contraction mappings with two metrics endowed with a directed graph. Furthermore, by using our main results, we are able to prove some results about coupled coincidence point endowed with a directed graph. Our results generalize the results obtained in $[2,12]$.

\section{Main Results}

Throughout this paper we shall say that $G$ will satisfy the standard conditions as mentioned in [5].

In addition, we will introduce the concept of $g$-Cauchy and edge preserving which are an effective tool as follows.

Definition 7. Let $(X, d)$ and $\left(Y, d^{\prime}\right)$ be two metric spaces, and let $f: X \rightarrow Y$ and $g: X \rightarrow X$ be two mappings. The mapping $f$ is said to be $g$-Cauchy on $X$ if, for any sequence $\left\{x_{n}\right\}$ in $X$ such that $\left\{g x_{n}\right\}$ is Cauchy sequence in $(X, d)$, then $\left\{f x_{n}\right\}$ is Cauchy sequence in $\left(Y, d^{\prime}\right)$.

It is easy to see that if $f$ is $g$-uniformly continuous on $X$, then $f$ is $g$-Cauchy on $X$.
Definition 8. Let $G$ be a directed graph, and let $f, g: X \rightarrow X$ be two mappings. We say that $f$ is $g$-edge preserving with respect to $G$ if

$$
(g x, g y) \in E(G) \Longrightarrow(f x, f y) \in E(G) .
$$

Let $\Phi$ denote the class of all functions $\phi:[0, \infty) \rightarrow$ $[0, \infty)$ which satisfy the following conditions:

$\left(\phi_{1}\right) \phi$ is nondecreasing.

$\left(\phi_{2}\right) \phi$ is continuous.

$\left(\phi_{3}\right) \phi(t)=0 \Leftrightarrow t=0$.

We now introduce a new class of the Geraghty type contractions in the following definition.

Definition 9. Let $(X, d)$ be a metric space endowed with a directed graph $G$, and let $f, g: X \rightarrow X$ be given mappings. The pair $(f, g)$ is called a $\theta-\phi$-contraction with respect to $d$ if

(1) $f$ is $g$-edge preserving with respect to $G$;

(2) there exist two functions $\theta \in \Theta$ and $\phi \in \Phi$ such that, for all $x, y \in X$ such that $(g x, g y) \in E(G)$,

$$
\phi(d(f x, f y)) \leq \theta(M(g x, g y)) \phi(M(g x, g y)),
$$

where $M(g x, g y)=\max \{d(g x, g y), d(g x, f x), d(g y$, $f y),(d(g x, f y)+d(g y, f x)) / 2\}$.

Let $(X, d)$ be a metric space endowed with a directed graph $G$ satisfying the standard conditions, and let two mappings $f, g: X \rightarrow X$ be given.

We define important subsets of $X$ as follows:

$$
\begin{aligned}
& X(f, g):=\{u \in X:(g u, f u) \in E(G)\}, \\
& C(f, g):=\{u \in X: f u=g u\}
\end{aligned}
$$

that is, the set of all coincidence points of mappings $f$ and $g$, and

$$
C m(f, g):=\{u \in X: f u=g u=u\},
$$

that is, the set of all common fixed points of mappings $f$ and $g$.

Now we are ready to present and prove the main results.

Theorem 10. Let $\left(X, d^{\prime}\right)$ be a complete metric space endowed with a directed graph $G$, and let $d$ be another metric on $X$. Suppose that $f, g: X \rightarrow X$ and $(f, g)$ is a $\theta$ - $\phi$-contraction with respect to $d$. Suppose that

(1) $g:\left(X, d^{\prime}\right) \rightarrow\left(X, d^{\prime}\right)$ is continuous and $g(X)$ is $d^{\prime}$ closed;

(2) $f(X) \subseteq g(X)$;

(3) $E(G)$ satisfies the transitivity property;

(4) if $d ¥ d^{\prime}$, one assumes that $f:(X, d) \rightarrow\left(X, d^{\prime}\right)$ is $g$-Cauchy on $X$;

(5) $f:\left(X, d^{\prime}\right) \rightarrow\left(X, d^{\prime}\right)$ is $G$-continuous, and $f$ and $g$ are $d^{\prime}$-compatible. 
Then, under these conditions,

$$
X(f, g) \neq \emptyset \quad \text { iff } C(f, g) \neq \emptyset .
$$

Proof. $(\Leftarrow)$ Suppose that $C(f, g) \neq \emptyset$. Let $u \in C(f, g)$. We have $f u=g u$. Then $(g u, f u)=(g u, g u) \in \Delta \subset E(G)$. Hence $(g u, g u)=(g u, f u) \in E(G)$ which means that $u \in X(f, g)$ and thus $X(f, g) \neq \emptyset$.

$(\Rightarrow)$ Suppose now $X(f, g) \neq \emptyset$. Let $x_{0} \in X$ such that $\left(g x_{0}, f x_{0}\right) \in E(G)$. By the assumption that $f(X) \subseteq g(X)$ and $f\left(x_{0}\right) \in X$, it easy to construct sequences $\left\{x_{n}\right\}$ in $X$ for which

$$
g x_{n}=f x_{n-1}
$$

for all $n \in \mathbb{N}$. If $g x_{n_{0}}=g x_{n_{0}-1}$ for some $n_{0} \in \mathbb{N}$, then $x_{n_{0}-1}$ is a coincidence point of the mappings $g$ and $f$. Therefore, we assume that, for each $n \in \mathbb{N}, g x_{n} \neq g x_{n-1}$ holds.

Since $\left(g x_{0}, f x_{0}\right)=\left(g x_{0}, g x_{1}\right) \in E(G)$ and $f$ is edge preserving with respect to $g$, we have $\left(f x_{0}, f x_{1}\right)=\left(g x_{1}\right.$, $\left.g x_{2}\right) \in E(G)$. Continuing inductively, we obtain that $\left(g x_{n-1}\right.$, $\left.g x_{n}\right) \in E(G)$ for each $n \in \mathbb{N}$. Hence it follows from the contractive condition that

$$
\begin{aligned}
& \phi\left(d\left(g x_{n+1}, g x_{n+2}\right)\right)=\phi\left(d\left(f x_{n}, f x_{n+1}\right)\right) \\
& \quad \leq \theta\left(M\left(g x_{n}, g x_{n+1}\right)\right) \phi\left(M\left(g x_{n}, g x_{n+1}\right)\right) \\
& \quad<\phi\left(M\left(g x_{n}, g x_{n+1}\right)\right) .
\end{aligned}
$$

On the other hand, we get

$$
\begin{aligned}
& M\left(g x_{n}, g x_{n+1}\right)=\max \left\{d\left(g x_{n}, g x_{n+1}\right), d\left(g x_{n}, f x_{n}\right),\right. \\
& \left.d\left(g x_{n+1}, f x_{n+1}\right), \frac{d\left(g x_{n}, f x_{n+1}\right)+d\left(g x_{n+1}, f x_{n}\right)}{2}\right\} \\
& =\max \left\{d\left(g x_{n}, g x_{n+1}\right), d\left(g x_{n+1}, g x_{n+2}\right),\right. \\
& \left.\quad \frac{d\left(g x_{n}, g x_{n+2}\right)}{2}\right\} \leq \max \left\{d\left(g x_{n}, g x_{n+1}\right),\right. \\
& \left.d\left(g x_{n+1}, g x_{n+2}\right)\right\} .
\end{aligned}
$$

If $M\left(g x_{n}, g x_{n+1}\right)=d\left(g x_{n+1}, g x_{n+2}\right)$, then, by (12), we obtain that

$$
\phi\left(d\left(g x_{n+1}, g x_{n+2}\right)\right)<\phi\left(d\left(g x_{n+1}, g x_{n+2}\right)\right)
$$

which is a contradiction. So, for all $n \geq 1$, we have

$$
M\left(g x_{n}, g x_{n+1}\right)=d\left(g x_{n}, g x_{n+1}\right) .
$$

Notice that, in view of (12), we get for all $n \geq 1$ that $\phi\left(d\left(g x_{n+1}, g x_{n+2}\right)\right)<\phi\left(d\left(g x_{n}, g x_{n+1}\right)\right)$. From $\phi_{1}$ of property of $\phi$, we have

$$
d\left(g x_{n+1}, g x_{n+2}\right) \leq d\left(g x_{n}, g x_{n+1}\right), \quad \forall n \in \mathbb{N} .
$$

Hence, we deduce that the sequence $\left\{d\left(g x_{n}, g x_{n+1}\right)\right\}$ is nonnegative and nonincreasing. Consequently, there exists $r \geq 0$ such that $\lim _{n \rightarrow \infty} d\left(g x_{n}, g x_{n+1}\right)=r$. We claim that $r=0$. Suppose, on the contrary, that $r>0$. Then, due to (12), we have

$$
\begin{aligned}
\frac{\phi\left(d\left(g x_{n+1}, g x_{n+2}\right)\right)}{\phi\left(d\left(g x_{n}, g x_{n+1}\right)\right)} & =\frac{\phi\left(d\left(g x_{n+1}, g x_{n+2}\right)\right)}{\phi\left(M\left(g x_{n}, g x_{n+1}\right)\right)} \\
& \leq \theta\left(M\left(g x_{n}, g x_{n+1}\right)\right)<1 .
\end{aligned}
$$

It follows that $\lim _{n \rightarrow \infty} \theta\left(M\left(g x_{n}, g x_{n+1}\right)\right)=1$. Owing to the fact that $\theta \in \Theta$, we get $\lim _{n \rightarrow \infty} M\left(g x_{n}, g x_{n+1}\right)=0$ which implies that $\lim _{n \rightarrow \infty} d\left(g x_{n}, g x_{n+1}\right)=0$, a contradiction. So, we conclude that

$$
\lim _{n \rightarrow \infty} d\left(g x_{n}, g x_{n+1}\right)=0 .
$$

We assert that $\left\{g x_{n}\right\}$ is a Cauchy sequence. Suppose, on the contrary, that $\left\{g x_{n}\right\}$ is not a Cauchy sequence. Thus, there exists $\epsilon>0$ such that, for all $k \in \mathbb{N}$, there exists $n(k), m(k) \epsilon$ $\mathbb{N}$ such that $n(k)>m(k) \geq k$ with the smallest number satisfying the condition below:

$$
\begin{gathered}
d\left(g x_{n_{k}}, g x_{m_{k}}\right) \geq \epsilon, \\
d\left(g x_{n_{k}-1}, g x_{m_{k}}\right)<\epsilon .
\end{gathered}
$$

Then, we have

$$
\begin{aligned}
\epsilon & \leq d\left(g x_{m_{k}}, g x_{n_{k}}\right) \\
& \leq d\left(g x_{m_{k}}, g x_{n_{k}-1}\right)+d\left(g x_{n_{k}-1}, g x_{n_{k}}\right) \\
& <\epsilon+d\left(g x_{n_{k}-1}, g x_{n_{k}}\right) .
\end{aligned}
$$

Letting $k \rightarrow \infty$ in the above inequality, by (18), we obtain that

$$
\lim _{n \rightarrow \infty} d\left(g x_{m_{k}}, g x_{n_{k}}\right)=\epsilon>0 .
$$

By the transitivity property of $E(G)$, we get $\left(g x_{m(k)}, g x_{n(k)}\right) \in$ $E(G)$ for all $k$. Thus, we have

$$
\begin{aligned}
& \phi\left(d\left(g x_{m(k)+1}, g x_{n(k)+1}\right)\right)=\phi\left(d\left(f x_{m(k)}, f x_{n(k)}\right)\right) \\
& \quad \leq \theta\left(M\left(g x_{m(k)}, g x_{n(k)}\right)\right) \phi\left(M\left(g x_{m(k)}, g x_{n(k)}\right)\right),
\end{aligned}
$$

where

$$
\begin{aligned}
& M\left(g x_{m(k)}, g x_{n(k)}\right)=\max \left\{d\left(g x_{m(k)}, g x_{n(k)}\right),\right. \\
& d\left(g x_{m(k)}, f x_{m(k)}\right), d\left(g x_{n(k)}, f x_{n(k)}\right), \\
& \left.\frac{d\left(g x_{m(k)}, f x_{n(k)}\right)+d\left(g x_{n(k)}, f x_{m(k)}\right)}{2}\right\} \\
& =\max \left\{d\left(g x_{m(k)}, g x_{n(k)}\right), d\left(g x_{m(k)}, g x_{m(k)+1}\right),\right. \\
& d\left(g x_{n(k)}, g x_{n(k)+1}\right), \\
& \left.\quad \frac{d\left(g x_{m(k)}, g x_{n(k)+1}\right)+d\left(g x_{n(k)}, g x_{m(k)+1}\right)}{2}\right\} .
\end{aligned}
$$


Hence, we conclude that

$$
\begin{aligned}
& \frac{\phi\left(d\left(g x_{m(k)+1}, g x_{n(k)+1}\right)\right)}{\phi\left(M\left(g x_{m(k)}, g x_{n(k)}\right)\right)} \leq \theta\left(M\left(g x_{m(k)}, g x_{n(k)}\right)\right) \\
& \quad<1 .
\end{aligned}
$$

Keeping (18) and (21) in mind and letting $k \rightarrow \infty$, we derive that

$$
\lim _{k \rightarrow \infty} M\left(g x_{m(k)}, g x_{n(k)}\right)=\epsilon>0 .
$$

By inequality (24), we get

$$
\lim _{k \rightarrow \infty} \theta\left(M\left(g x_{m(k)}, g x_{n(k)}\right)\right)=1
$$

and hence $\lim _{k \rightarrow \infty} M\left(g x_{m(k)}, g x_{n(k)}\right)=0$, a contradiction. So, we conclude that $\left\{g x_{n}\right\}$ is a Cauchy sequence in $(X, d)$.

Next, we claim that $\left\{g x_{n}\right\}$ is a Cauchy sequence with respect to $d^{\prime}$.

If $d \geq d^{\prime}$, it is trivial. Thus, suppose $d \ngtr d^{\prime}$. Let $\varepsilon>0$. Since $\left\{g x_{n}\right\}$ is a Cauchy sequence in $(X, d)$ and $f$ is $g$-Cauchy on $X$, we have that $\left\{f x_{n}\right\}$ is Cauchy sequence in $\left(X, d^{\prime}\right)$. Then there exists $N_{0} \in \mathbb{N}$ with

$$
d^{\prime}\left(g x_{n+1}, g x_{m+1}\right)=d^{\prime}\left(f x_{n}, f x_{m}\right)<\varepsilon
$$

whenever $n, m \geq N_{0}$. So $\left\{g x_{n}\right\}$ is a Cauchy sequence with respect to $d^{\prime}$.

Since $g(X)$ is a $d^{\prime}$-closed subset of the complete metric space $\left(X, d^{\prime}\right)$, there exists $u=g x \in g(X)$ such that

$$
\lim _{n \rightarrow \infty} g x_{n}=\lim _{n \rightarrow \infty} f x_{n}=u \text {. }
$$

Now, since $f:\left(X, d^{\prime}\right) \rightarrow\left(X, d^{\prime}\right)$ is G-continuous, and $f$ and $g$ are $d^{\prime}$-compatible, we have

$$
\lim _{n \rightarrow \infty} d^{\prime}\left(g f x_{n}, f g x_{n}\right)=0 .
$$

Using the triangle inequality, we have

$$
\begin{aligned}
d^{\prime}(g u, f u) \leq & d^{\prime}\left(g u, g f x_{n}\right)+d^{\prime}\left(g f x_{n}, f g x_{n}\right) \\
& +d^{\prime}\left(f g x_{n}, f u\right) .
\end{aligned}
$$

Letting $n \rightarrow \infty$, from (29), the continuity of $g$, and the $G$ continuity of $f$, it follows that $d^{\prime}(g u, f u)=0$ which implies that $g u=f u$. So $u$ is a coincidence point of $f$ and $g$.

If $d=d^{\prime}$, we have the following theorem.

Theorem 11. Let $(X, d)$ be a complete metric space endowed with a directed graph $G$. Suppose that $f, g: X \rightarrow X$ and $(f, g)$ is a $\theta$ - $\phi$-contraction with respect to $d$. Moreover, suppose that

(1) $g$ is continuous and $g(X)$ is closed;

(2) $f(X) \subseteq g(X)$;

(3) $E(G)$ satisfies the transitivity property;

(4) (a) $f$ is $G$-continuous and $f$ and $g$ are $d$-compatible or (b) $(X, d, G)$ has property $A$.
Then, under these conditions,

$$
X(f, g) \neq \emptyset \quad \text { iff } C(f, g) \neq \emptyset \text {. }
$$

Proof. In order to avoid the repetition, following from the same proof in Theorem 10, we can only consider (b) of condition (3). Since $\left\{g x_{n}\right\}$ is a Cauchy sequence in $(X, d)$ and $g(X)$ is closed in $X$, there exists $u \in X$ such that

$$
\lim _{n \rightarrow \infty} g x_{n}=g u=\lim _{n \rightarrow \infty} f x_{n}
$$

Now, we show that $u$ is a coincidence point of $f$ and $g$. Suppose, on the contrary, that $f u \neq g u$. Then $d(f u, g u)>0$. Since $(X, d, G)$ has property $A$, we have $\left(g x_{n}, g u\right) \in E(G)$ for each $n \in \mathbb{N}$. By using the triangle inequality, we derive

$$
d(g u, f u) \leq d\left(g u, f x_{n(k)}\right)+d\left(f x_{n(k)}, f u\right)
$$

which implies that

$$
d(g u, f u)-d\left(g u, f x_{n(k)}\right) \leq d\left(f x_{n(k)}, f u\right) .
$$

By the property of $\phi$, we obtain that

$$
\begin{gathered}
\phi\left(d(g u, f u)-d\left(g u, f x_{n(k)}\right)\right) \leq \phi\left(d\left(f x_{n(k)}, f u\right)\right) \\
\leq \theta\left(M\left(g x_{n(k)}, g u\right)\right) \phi\left(M\left(g x_{n(k)}, g u\right)\right),
\end{gathered}
$$

where

$$
\begin{gathered}
M\left(g x_{n(k)}, g u\right)=\max \left\{d\left(g x_{n(k)}, g u\right),\right. \\
d\left(g x_{n(k)}, f x_{n(k)}\right), d(g u, f u), \\
\left.\frac{d\left(g x_{n(k)}, f u\right)+d\left(g u, f x_{n(k)}\right)}{2}\right\} .
\end{gathered}
$$

From (32), we obtain that

$$
\lim _{k \rightarrow \infty} M\left(g x_{n(k)}, g u\right)=d(g u, f u)>0 .
$$

Letting $k \rightarrow \infty$ in inequality (35), we obtain that $\lim _{k \rightarrow \infty} \theta\left(M\left(g x_{n(k)}, g u\right)\right)=1$ so $\lim _{k \rightarrow \infty} M\left(g x_{n(k)}, g u\right)=$ $d(g u, f u)=0$, a contradiction. Therefore $f u=g u$. Consequently, we conclude that $f$ and $g$ have a coincidence point.

Theorem 12. In addition to the hypotheses of Theorem 10, assume that

(K) for any $x, y \in C(f, g)$ such that $g x \neq g y$, we have $(g x, g y) \in E(G)$.

If $f$ and $g$ are $d^{\prime}$-compatible and $X(f, g) \neq \emptyset$, then $C m(f, g) \neq$ $\emptyset$.

Proof. Theorem 10 implies that there exists a coincidence point $x \in X$; that is, $g x=f x$. Suppose that there exists another coincidence point $y \in X$ such that $g y=f y$. Assume 
that $g x \neq g y$. By assumption $(\mathrm{K}),(g x, g y) \in E(G)$, and we have

$$
\begin{aligned}
\phi(d(f x, f y)) & \leq \theta(M(g x, g y)) \phi(M(g x, g y)) \\
& <\phi(M(g x, g y))=\phi(d(f x, f y)),
\end{aligned}
$$

which is a contradiction. Therefore, $g x=g y$. Starting from $x_{0}=x$, choose the sequences $\left\{x_{n}\right\}$ satisfying $g x_{n}=f x_{n-1}$ for each $n \in \mathbb{N}$. Taking into account the properties of coincidence points, it is easy to see that it can be done so that $x_{n}=x$; that is,

$$
g x_{n}=f x
$$

for all $n \in \mathbb{N}$. Next, set $w=g x$ so we get $g w=g g x=g f x$. The definition of the sequence $\left\{x_{n}\right\}$ implies that $g x_{n}=f x=f x_{n-1}$ for all $n \in \mathbb{N}$ and hence

$$
\lim _{n \rightarrow \infty} f x_{n}=\lim _{n \rightarrow \infty} g x_{n}=f x
$$

with respect to $d^{\prime}$. Because $g$ and $f$ are $d^{\prime}$-compatible, we have

$$
\lim _{n \rightarrow \infty} d^{\prime}\left(g f x_{n}, f g x_{n}\right)=0
$$

that is, $g f x=f g x$. Therefore, we have $g w=g f x=f g x=f w$ which we can conclude that $w$ is another coincidence point of the functions $f$ and $g$. By the above results, we obtain $f w=$ $g w=g x=w$ and so $w$ is a common fixed point of $g$ and $f$. In other words, $C m(f, g) \neq \emptyset$.

If $M(g x, g y)=d(g x, g y)$, we get the following.

Definition 13. Let $(X, d)$ be a metric space endowed with a directed graph $G$, and let $f, g: X \rightarrow X$ be given mappings. The pair $(f, g)$ is called a $\theta-\psi$-contraction with respect to $d$ if

(1) $f$ is $g$-edge preserving with respect to $G$;

(2) there exist two functions $\theta \in \Theta$ and $\psi \in \Phi$ such that for all $x, y \in X$ such that $(g x, g y) \in E(G)$,

$$
\psi(d(f x, f y)) \leq \theta(d(g x, g y)) \psi(d(g x, g y)) .
$$

Applying the similar argument as in the proof of Theorems 10 and 11, we have the following.

Corollary 14. Let $\left(X, d^{\prime}\right)$ be a complete metric space endowed with a directed graph $G$, and let $d$ be another metric on $X$. Suppose that $f, g: X \rightarrow X$ and $(f, g)$ is a $\theta-\psi$-contraction with respect to $d$. Moreover, suppose that

(1) $g:\left(X, d^{\prime}\right) \rightarrow\left(X, d^{\prime}\right)$ is continuous and $g(X)$ is $d^{\prime}$ closed;

(2) $f(X) \subseteq g(X)$;

(3) $E(G)$ satisfies the transitivity property;

(4) if $d ¥ d^{\prime}$, one assumes that $f:(X, d) \rightarrow\left(X, d^{\prime}\right)$ is $g$-Cauchy on $X$;

(5) (a) $f$ is G-continuous, and $f$ and $g$ are $d$-compatible or $(b)$ if $d=d^{\prime}$, assume that $(X, d, G)$ has property $A$.
Then, under these conditions,

$$
X(f, g) \neq \emptyset \quad \text { iff } C(f, g) \neq \emptyset \text {. }
$$

Remark 15. Put $E(G)=\{(x, y) \in X \times X: x \preceq y\}$ and $\psi(t)=t$ in Corollary 14. In this case, we obtain the results of [2].

Example 16. Let $X=[0, \infty) \subseteq \mathbb{R}$, and let the metrics $d, d^{\prime}$ : $X \times X \rightarrow[0, \infty)$ be defined by

$$
\begin{gathered}
d(x, y)=|x-y|, \\
d^{\prime}(x, y)=L|x-y|
\end{gathered}
$$

for all $x, y \in X$, respectively, where $L$ is a constant real number such that $L \in(1, \infty)$. It is easy to see that $d<d^{\prime}$.

Now, we consider $E(G)$ given by

$$
E(G)=\{(x, y): x=y \text { or } x, y \in[0,1] \text { with } x \leq y\} .
$$

Consider the mappings $f: X \rightarrow X$ and $g: X \rightarrow X$ defined by

$$
\begin{aligned}
& g x=x^{2}, \\
& f x=\ln \left(1+\frac{x^{2}}{2}\right)
\end{aligned}
$$

for all $x \in X$, respectively.

Next, we show that conditions (1)-(2) in Definition 13 hold as follows.

(1) Let $(g x, g y) \in E(G)$, if $x=y$ then $(f x, f y) \in E(G)$, if $g x, g y \in E(G)$ with $g x \leq g y$, then we obtain $g x=x^{2}$, $g y=y^{2} \in[0,1]$ and $x^{2}=g x \leq g y=y^{2}$, and we have $f x=\ln \left(1+x^{2} / 2\right) \leq f y=\ln \left(1+y^{2} / 2\right)$ and $f x, f y \in[0,1]$. This implies that $(f x, f y) \in E(G)$.

(2) Let $\psi(t)=t / 2$, and let $\theta \in \Theta$ be defined by

$$
\theta(t)= \begin{cases}\frac{2 \ln (1+t / 2)}{t}, & \text { if } t>0, \\ 0, & \text { if } t=0 .\end{cases}
$$

Let $x, y$ be arbitrary points in $X$ and $(g x, g y) \in E(G)$. If $g x=$ $g y$, we have $x=y$ and hence the contractive condition (42) holds for this case. In another case, we have $g x=x^{2}, g y=$ $y^{2} \in[0,1]$, and $x^{2}=g x \leq g y=y^{2}$. Also, we have 


$$
\begin{aligned}
\psi & (d(f x, f y))=\frac{d(f x, f y)}{2} \\
& =\frac{\left|\ln \left(1+x^{2} / 2\right)-\ln \left(1+y^{2} / 2\right)\right|}{2} \\
& =\frac{\ln \left(1+y^{2} / 2\right)-\ln \left(1+x^{2} / 2\right)}{2} \\
& =\frac{\ln \left(\left(1+y^{2} / 2\right) /\left(1+x^{2} / 2\right)\right)}{2} \\
& =\frac{\ln \left(1+\left(y^{2} / 2-x^{2} / 2\right) /\left(1+x^{2} / 2\right)\right)}{2} \\
& \leq \frac{\ln \left(1+\left|x^{2} / 2-y^{2} / 2\right|\right)}{2} \\
& \leq \frac{2 \ln \left(1+(1 / 2)\left|x^{2}-y^{2}\right|\right)\left|x^{2}-y^{2}\right|}{\left|x^{2}-y^{2}\right|} \\
& =\frac{2 \ln (1+(1 / 2) d(g x, g y))}{d(g x, g y)} \psi(d(g x, g y)) \\
& =\theta(d(g x, g y)) \psi(d(g x, g y)) .
\end{aligned}
$$

Therefore, condition (3) holds for the functions $\theta$ and $\psi$.

Next, the proof for conditions (1)-(5) in Corollary 14 is shown as follows.

(1) The function $g:\left(X, d^{\prime}\right) \rightarrow\left(X, d^{\prime}\right)$ can be easily seen to be continuous. Moreover, we immediately obtain that $g(X)=$ $[0, \infty)$ is $d^{\prime}$-closed.

(2) By the construction of $f$ and $g$, we can conclude that $f(X)=g(X)$.

(3) $E(G)$ is clearly satisfying the transitivity property.

(4) Since $d<d^{\prime}$, we need to prove that the function $f:(X, d) \rightarrow\left(X, d^{\prime}\right)$ is $g$-Cauchy on $X$. Let $\epsilon>0$, and let $\left\{x_{n}\right\}$ be a sequence in $X$ such that $\left\{g x_{n}\right\}$ is a Cauchy sequence in $(X, d)$. Then, there exist $K \in \mathbb{N}$ such that, for all $n, m \geq$ $K, d\left(g x_{n}, g x_{m}\right)<\epsilon / L$. Then we have

$$
\begin{aligned}
& d^{\prime}\left(f x_{n}, f x_{m}\right)=L\left|f x_{n}-f y_{m}\right|=L \mid \ln \left(1+\frac{\left(x_{n}\right)^{2}}{2}\right) \\
& -\ln \left(1+\frac{\left(x_{m}\right)^{2}}{2}\right)|=L| \ln \frac{1+\left(x_{m}\right)^{2} / 2}{1+\left(x_{n}\right)^{2} / 2} \mid \\
& \quad=L\left|\ln \left(1+\frac{\left(x_{m}\right)^{2} / 2-\left(x_{n}\right)^{2} / 2}{1+\left(x_{n}\right)^{2} / 2}\right)\right| \\
& \quad \leq L\left[\ln \left(1+\left|\frac{\left(x_{n}\right)^{2}}{2}-\frac{\left(x_{m}\right)^{2}}{2}\right|\right)\right] \\
& \quad \leq L\left[\frac{2 \ln \left(1+(1 / 2)\left|\left(x_{n}\right)^{2}-\left(x_{m}\right)^{2}\right|\right)}{\left|\left(x_{n}\right)^{2}-\left(x_{m}\right)^{2}\right|} \mid\left(x_{n}\right)^{2}\right.
\end{aligned}
$$

$$
\begin{aligned}
& \left.-\left(x_{m}\right)^{2} \mid\right]<L\left|\left(x_{n}\right)^{2}-\left(x_{m}\right)^{2}\right|=L d\left(g x_{n}, g x_{m}\right) \\
& <L \frac{\epsilon}{L}=\epsilon .
\end{aligned}
$$

This implies that $f:(X, d) \rightarrow\left(X, d^{\prime}\right)$ is $g$-Cauchy on $X$.

(5) It can be easily shown that $f:\left(X, d^{\prime}\right) \rightarrow\left(X, d^{\prime}\right)$ is $G$ continuous. As a result, we will only need to prove that $g$ and $f$ are $d^{\prime}$-compatible. Let $\left\{x_{n}\right\}$ be a sequence in $X$ such that

$$
\lim _{n \rightarrow \infty} g x_{n}=\lim _{n \rightarrow \infty} f x_{n}=a .
$$

Then we have $\ln (1+a / 2)=a$ and so it follows that $a=0$. Now, we have

$$
\begin{aligned}
& d^{\prime}\left(g f x_{n}, f g x_{n}\right) \\
& =L\left|\left(\ln \left(1+\frac{\left(x_{n}\right)^{2}}{2}\right)\right)^{2}-\ln \left(1+\frac{\left(x_{n}\right)^{4}}{2}\right)\right| \rightarrow 0
\end{aligned}
$$

as $n \rightarrow \infty$.

It is easy to see that there exists a point $x_{0} \in X$ such that $\left(g x_{0}, f x_{0}\right) \in E(G)$, and this implies that $X(f, g) \neq \emptyset$.

Consequently, all the conditions of Corollary 14 hold. Therefore, $g$ and $f$ have a coincidence point and, furthermore, a point 0 is a coincidence point of the mappings $g$ and $f$.

\section{Coupled Coincidence Point Theorems}

We begin with some useful background.

Definition 17 (see [4]). Let $(X, d)$ be a metric space, and let $g: X \rightarrow X$ and $F: X \times X \rightarrow X$. The mappings $g$ and $F$ are said to be $d$-compatible if

$$
\begin{aligned}
& \lim _{n \rightarrow \infty} d\left(g F\left(x_{n}, y_{n}\right), F\left(g x_{n}, g y_{n}\right)\right)=0, \\
& \lim _{n \rightarrow \infty} d\left(g F\left(y_{n}, x_{n}\right), F\left(g y_{n}, g x_{n}\right)\right)=0
\end{aligned}
$$

hold whenever $\left\{x_{n}\right\}$ and $\left\{y_{n}\right\}$ are sequences in $X$ such that $\lim _{n \rightarrow \infty} F\left(x_{n}, y_{n}\right)=\lim _{n \rightarrow \infty} g x_{n}$ and $\lim _{n \rightarrow \infty} F\left(y_{n}, x_{n}\right)=$ $\lim _{n \rightarrow \infty} g y_{n}$.

Let $X$ be a nonempty set, and let $F: X^{2} \rightarrow X$ and $g$ : $X \rightarrow X$ be two mappings.

We define two mappings $T_{F}, G_{g}: X \times X \rightarrow X \times X$ by

$$
\begin{aligned}
T_{F}(x, y) & =(F(x, y), F(y, x)), \\
G_{g}(x, y) & =(g x, g y)
\end{aligned}
$$

for all $x, y \in X$.

The following lemma guarantees that 2-dimensional notion of common fixed coincidence points can be interpreted in terms of two mappings $T_{F}$ and $G_{g}$. 
Lemma 18 (see [2]). Suppose that $X$ is a nonempty set and $F: X \times X \rightarrow X$ and $g: X \rightarrow X$ are functions. We say that the point $\left(x_{1}, x_{2}\right) \in X \times X$ is a coupled coincidence point of $F$ and $g$, that is, $g x=F(x, y)$ and $g y=F(y, x)($ see $[13,14])$, if and only if it is a coincidence point of the functions $T_{F}$ and $G_{g}$.

Definition 19. Suppose that $G$ is a directed graph and $F: X \times$ $X \rightarrow X$ and $g: X \rightarrow X$ are two functions. $F$ is said to be $G$ edge preserving with respect to $g$ if and only if the following holds:

$$
\begin{aligned}
\text { If } & (g x, g u),(g y, g v) \in E(G), \\
\text { then } & (F(x, y), F(u, v)),(F(y, x), F(v, u)) \\
& \in E(G) .
\end{aligned}
$$

The concept of the cross product of the graphs $G_{i}=$ $\left(V\left(G_{i}\right), E\left(G_{i}\right)\right), i=1,2$, is defined by

$$
G_{1} \times G_{2}:=\left(V\left(G_{1} \times G_{2}\right), E\left(G_{1} \times G_{2}\right)\right),
$$

where $E\left(G_{1} \times G_{2}\right)=\left\{\left((x, y),\left(x^{\prime}, y^{\prime}\right)\right) \mid\left(x, x^{\prime}\right) \in E\left(G_{1}\right)\right.$ and $\left.\left(y, y^{\prime}\right) \in E\left(G_{2}\right)\right\}$.

Now, the following lemma shows that being edge preserving and the transitivity property for 2-dimensional case can be interpreted in terms of two mappings $T_{F}$ and $G_{g}$.

Lemma 20. Let $F: X^{2} \rightarrow X$ and $g: X \rightarrow X$ be two mappings, and let $(X, d)$ be a metric space endowed with a directed graph $G$. Then, $F$ is $G$-edge preserving with respect to $g$ if and only if $T_{F}$ is edge preserving with respect to $G_{g}$.

Proof. $(\Rightarrow)$ Let $F$ be $G$-edge preserving with respect to $g$, and let $x, y, u$, and $v \in X$ be such that

$$
\begin{aligned}
& \left(G_{g}(x, y), G_{g}(u, v)\right) \in E(G \times G) \\
& \Downarrow \\
& ((g x, g y),(g u, g v)) \in E(G \times G) \\
& \Downarrow \\
& (g x, g u) \in E(G), \\
& (g y, g v) \in E(G) \\
& \Downarrow \\
& (F(x, y), F(u, v)) \in E(G), \\
& (F(y, x), F(v, u)) \in E(G) \\
& \Downarrow \\
& ((F(x, y), F(y, x)),(F(u, v), F(v, u))) \in E(G \times G) \\
& \Downarrow \\
& \left(T_{F}(x, y), T_{F}(u, v)\right) \in E(G \times G) .
\end{aligned}
$$

$(\Leftarrow)$ Let $T_{F}$ be edge preserving with respect to $G_{g}$, and let $x, y, u$, and $v \in X$ be such that

$$
\begin{aligned}
(g x, g u) & \in E(G), \\
(g y, g v) & \in E(G) \\
\Downarrow & \\
((g x, g y),(g u, g v)) & \in E(G \times G) \\
\Downarrow & \\
\left(G_{g}(x, y), G_{g}(u, v)\right) & \in E(G \times G) \\
\Downarrow & \\
\Downarrow & \left(T_{F}(x, y), T_{F}(u, v)\right) \in E(G \times G) \\
((F(x, y), F(y, x)),(F(u, v), F(v, u))) & \in E(G \times G) \\
\Downarrow & \\
(F(x, y), F(u, v)) & \in E(G), \\
(F(y, x), F(v, u)) & \in E(G) .
\end{aligned}
$$

Lemma 21. Let $F: X^{2} \rightarrow X$ and $g: X \rightarrow X$ be two mappings, and let $(X, d)$ be a metric space endowed with directed graphs $G_{1}$ and $G_{2}$. Then, $E\left(G_{1}\right)$ and $E\left(G_{2}\right)$ satisfy the transitivity property if and only if $E\left(G_{1} \times G_{2}\right)$ satisfies the transitivity property.

Proof. $(\Rightarrow)$ Suppose that $E\left(G_{1}\right)$ and $E\left(G_{2}\right)$ satisfy the transitivity property. Let $x, y, u, v, a$, and $b \in X$ be such that

$$
\begin{aligned}
&((x, y),(u, v)),((u, v),(a, b)) \in E\left(G_{1} \times G_{2}\right) \\
& \Downarrow \\
&(x, u),(u, a) \in E\left(G_{1}\right), \\
&(y, v),(v, b) \in E\left(G_{2}\right) \\
& \Downarrow \\
&(x, a) \in E\left(G_{1}\right), \\
&(y, b) \in E\left(G_{2}\right) \\
& \Downarrow \\
&((x, y),(a, b)) \in E\left(G_{1} \times G_{2}\right) .
\end{aligned}
$$

$(\Leftarrow)$ Suppose that $E\left(G_{1} \times G_{2}\right)$ satisfies the transitivity property. Let $x, y, u, v, a$, and $b \in X$ be such that 


$$
\begin{aligned}
&(x, u),(u, a) \in E\left(G_{1}\right), \\
&(y, v),(v, b) \in E\left(G_{2}\right) \\
& \Downarrow \\
&((x, y),(u, v)),((u, v),(a, b)) \in E\left(G_{1} \times G_{2}\right) \\
& \Downarrow \\
&((x, y),(a, b)) \\
& \Downarrow E\left(G_{1} \times G_{2}\right) \\
& \Downarrow \\
&(x, a) \in E\left(G_{1}\right), \\
&(y, b) \in E\left(G_{2}\right) .
\end{aligned}
$$

Let $(X, d)$ be a metric space endowed with a directed graph $G$ satisfying the standard conditions, and let $F: X \times$ $X \rightarrow X$ and $g: X \rightarrow X$ be two functions. We will define the following sets:

$$
\begin{aligned}
& \left(X^{2}\right)_{g}^{F}=\left\{(x, y) \in X^{2}:(g x, F(x, y)),(g y, F(y, x))\right. \\
& \quad \in E(G)\} \\
& \operatorname{CcFix}(F)=\left\{(x, y) \in X^{2}: F(x, y)=g x, F(y, x)\right. \\
& \quad=g y\} .
\end{aligned}
$$

Suantai et al. gave the notion of a $\theta-\psi$-contraction as in [12]. We are ready to present an application of Corollary 14 in order to deduce results about coupled fixed points.

Theorem 22. Let $\left(X, d^{\prime}\right)$ be a complete metric space endowed with a directed graph $G$, let $d: X \times X \rightarrow[0,+\infty)$ be another metric on $X$, and let $F: X \times X \rightarrow X$ and $g: X \rightarrow X$ be two functions so that the pair of $F$ and $g$ is a $\theta-\psi$-contraction. Suppose that the following are true:
(1) $g:\left(X, d^{\prime}\right) \rightarrow\left(X, d^{\prime}\right)$ is a continuous function such that $g(X)$ is $d^{\prime}$-closed.

(2) $F(X \times X)$ is a subset of $g(X)$.

(3) $E(G)$ satisfies the transitivity property.

(4) if $d ¥ d^{\prime}$, then assume further that $F:(X, d) \times(X, d) \rightarrow$ $\left(X, d^{\prime}\right)$ is $g$-uniformly continuous on $X \times X$.

(5) (a) $F:\left(X, d^{\prime}\right) \times\left(X, d^{\prime}\right) \rightarrow\left(X, d^{\prime}\right)$ is G-continuous, and $F$ and $g$ are $d^{\prime}$-compatible or (b) if $d=d^{\prime}$, assume that $(X, d, G)$ has property $A$.

Under these conditions $\operatorname{CcFix}(F) \neq \emptyset$ if and only if $\left(X^{2}\right)_{g}^{F} \neq \emptyset$.

Proof. We only need to apply Corollary 14 to the functions $T_{F}$ and $G_{g}$ on the complete metric space $\left(X \times X, D^{\prime}\right)$ and the metric space $(X \times X, D)$, where the metrics $D$ and $D^{\prime}$ are defined as follows:

$$
\begin{gathered}
D^{\prime}((x, y),(u, v))=\max \left\{d^{\prime}(x, u), d^{\prime}(y, v)\right\}, \\
D((x, y),(u, v))=\max \{d(x, u), d(y, v)\} .
\end{gathered}
$$

If we put $G^{*}=G \times G$, we have

$$
((x, y),(u, v)) \in E\left(G^{*}\right) \Longleftrightarrow(x, u),(y, v) \in E(G)
$$

for all $(x, y),(u, v) \in X \times X$.

By Lemmas 20 and 21, we have that $T_{F}: X \times X \rightarrow X \times X$ is $G_{g}$-edge preserving with respect to $G^{*}$ and $E\left(G^{*}\right)$ satisfies the transitivity property. Since the pair of $F$ and $g$ is a $\theta-\psi$ contraction, we get that $\left(T_{F}, G_{g}\right)$ is a $\theta-\psi$-contraction with respect to $d$. Since $F(X \times X) \subseteq g(X)$, for any given $x_{0}, y_{0} \in X$, we can construct sequences $\left\{g x_{n}\right\},\left\{g y_{n}\right\}$ for which

$$
\begin{aligned}
& g x_{n}=F\left(x_{n-1}, y_{n-1}\right), \\
& g y_{n}=F\left(y_{n-1}, x_{n-1}\right)
\end{aligned}
$$

$\forall n \in \mathbb{N}$.

From this, it easy to see that if $F$ is $G$-continuous, then $T_{F}$ is $G$-continuous. Observe that

Notice that $F$ and $g$ are $d^{\prime}$-compatible. $\Longleftrightarrow$

$$
\begin{aligned}
& {\left[\left\{\begin{array}{c}
\lim _{n \rightarrow \infty} F\left(x_{n}, y_{n}\right)=\lim _{n \rightarrow \infty} g x_{n} \\
\lim _{n \rightarrow \infty} F\left(y_{n}, x_{n}\right)=\lim _{n \rightarrow \infty} g y_{n}
\end{array}\right\} \Longrightarrow\left\{\begin{array}{l}
\lim _{n \rightarrow \infty} d^{\prime}\left(g F\left(x_{n}, y_{n}\right), F\left(g x_{n}, g y_{n}\right)\right)=0 \\
\lim _{n \rightarrow \infty} d^{\prime}\left(g F\left(y_{n}, x_{n}\right), F\left(g y_{n}, g x_{n}\right)\right)=0
\end{array}\right\} \Longleftrightarrow\right.} \\
& {\left[\lim _{n \rightarrow \infty} T_{F}\left(x_{n}, y_{n}\right)=\lim _{n \rightarrow \infty} G_{g}\left(x_{n}, y_{n}\right) \Longrightarrow \lim _{n \rightarrow \infty} D^{\prime}\left(T_{F} G_{g}\left(x_{n}, y_{n}\right), G_{g} T_{F}\left(x_{n}, y_{n}\right)\right)=0\right] \Longleftrightarrow}
\end{aligned}
$$

$T_{F}$ and $G_{g}$ are $D^{\prime}$-compatible.

This completes the proof.

Taking $d=d^{\prime}$ in Theorem 22, we have the following Corollary which implies the result in [12].
Corollary 23. Let $(X, d)$ be a complete metric space endowed with a directed graph $G$, and let $F: X \times X \rightarrow X$ and $g$ : $X \rightarrow X$ be two mappings such that the pair of $F$ and $g$ is a $\theta-\psi$-contraction. Suppose that the following hold: 
(1) $g$ is continuous and $g(X)$ is closed.

(2) $F(X \times X) \subseteq g(X)$.

(3) $E(G)$ satisfies the transitivity property.

(4) (a) $F:\left(X, d^{\prime}\right) \times\left(X, d^{\prime}\right) \rightarrow\left(X, d^{\prime}\right)$ is G-continuous and $F$ and $g$ are compatible or $(b)(X, d, G)$ has property $A$.

Under these conditions $\operatorname{CcFix}(F) \neq \emptyset$ if and only if $\left(X^{2}\right)_{g}^{F} \neq \emptyset$.

\section{Conflicts of Interest}

The authors declare that they have no conflicts of interest.

\section{Acknowledgments}

This research is supported by Chiang Mai University, Thailand.

\section{References}

[1] M. A. Geraghty, "On contractive mappings," Proceedings of the American Mathematical Society, vol. 40, pp. 604-608, 1973.

[2] J. Martínez-Moreno, W. Sintunavarat, and Y. J. Cho, "Common fixed point theorems for Geraghty's type contraction mappings using the monotone property with two metrics," Fixed Point Theory and Applications, vol. 2015, no. 1, article no. 174, 2015.

[3] G. Jungck, "Compatible mappings and common fixed points," International Journal of Mathematics and Mathematical Sciences, vol. 9, no. 4, pp. 771-779, 1986.

[4] B. S. Choudhury and A. Kundu, "A coupled coincidence point result in partially ordered metric spaces for compatible mappings," Nonlinear Analysis. Theory, Methods \& Applications. An International Multidisciplinary Journal, vol. 73, no. 8, pp. 2524-2531, 2010.

[5] J. Jachymski, "The contraction principle for mappings on a metric space with a graph," Proceedings of the American Mathematical Society, vol. 136, no. 4, pp. 1359-1373, 2008.

[6] M. R. Alfuraidan, "The contraction principle for multivalued mappings on a modular metric space with a graph," Canadian Mathematical Bulletin, vol. 59, no. 1, pp. 3-12, 2016.

[7] M. R. Alfuraidan, "Remarks on monotone multivalued mappings on a metric space with a graph," Journal of Inequalities and Applications, vol. 2015, no. 1, article no. 202, 2015.

[8] M. R. Alfuraidan and M. A. Khamsi, "Caristi fixed point theorem in metric spaces with a graph," Abstract and Applied Analysis, vol. 2014, Article ID 303484, 2014.

[9] M. R. Alfuraidan, "Remarks on Caristi's fixed point theorem in metric spaces with a graph," Fixed Point Theory and Applications, vol. 2014, no. 1, article no. 240, 2014.

[10] I. Beg, A. R. Butt, and S. Radojevic, "The contraction principle for set valued mappings on a metric space with a graph," Computers \& Mathematics with Applications. An International Journal, vol. 60, no. 5, pp. 1214-1219, 2010.

[11] F. Bojor, "Fixed point theorems for Reich type contractions on metric spaces with a graph," Nonlinear Analysis. Theory, Methods \& Applications. An International Multidisciplinary Journal, vol. 75, no. 9, pp. 3895-3901, 2012.

[12] S. Suantai, P. Charoensawan, and T. A. Lampert, "Common coupled fixed point theorems for $\theta-\psi$-contraction mappings endowed with a directed graph," Fixed Point Theory and Applications, vol. 2015, no. 1, article no. 224, pp. 1-11, 2015.
[13] T. Gnana Bhaskar and V. Lakshmikantham, "Fixed point theorems in partially ordered metric spaces and applications," Nonlinear Analysis. Theory, Methods \& Applications. An International Multidisciplinary Journal, vol. 65, no. 7, pp. 1379-1393, 2006.

[14] V. Lakshmikantham and L. Ciric, "Coupled fixed point theorems for nonlinear contractions in partially ordered metric spaces," Nonlinear Analysis. Theory, Methods \& Applications. An International Multidisciplinary Journal, vol. 70, no. 12, pp. 43414349, 2009. 


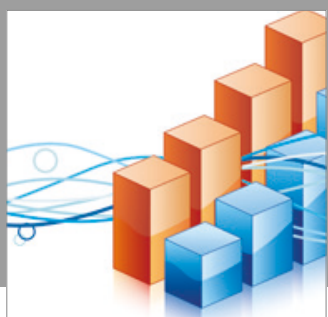

Advances in

Operations Research

vatersals

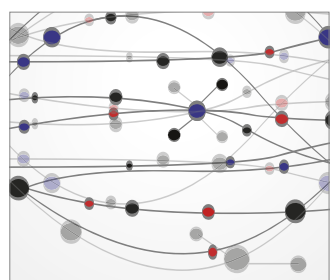

\section{The Scientific} World Journal
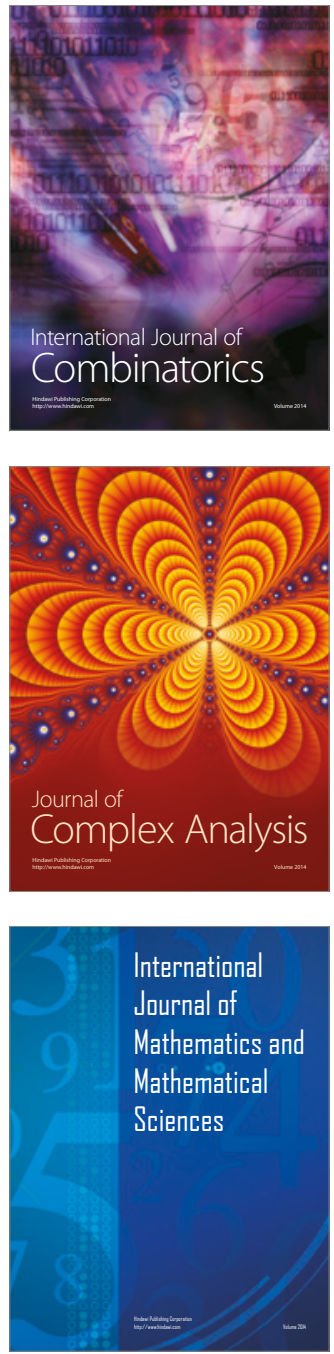
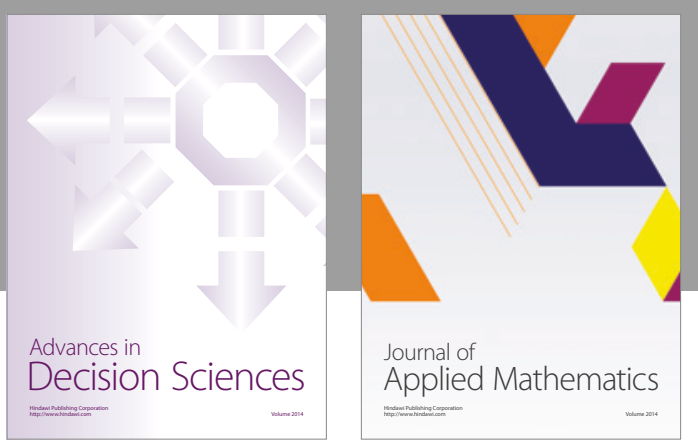

Algebra

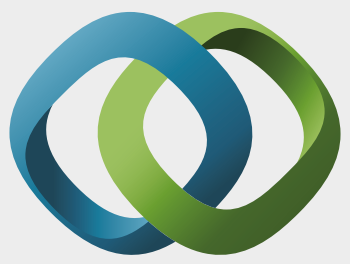

\section{Hindawi}

Submit your manuscripts at

https://www.hindawi.com
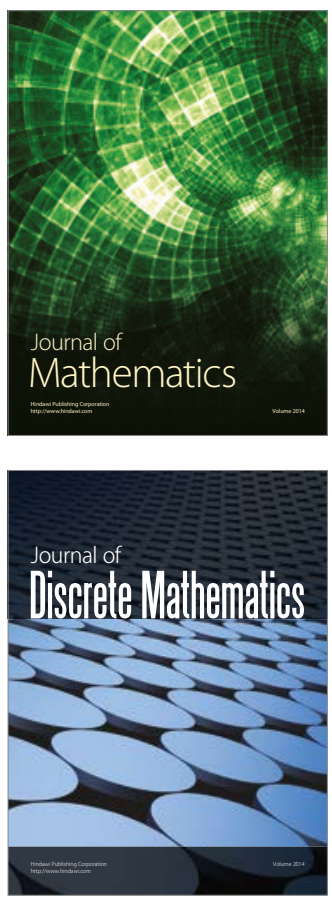

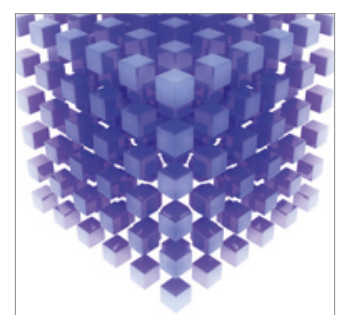

Mathematical Problems in Engineering
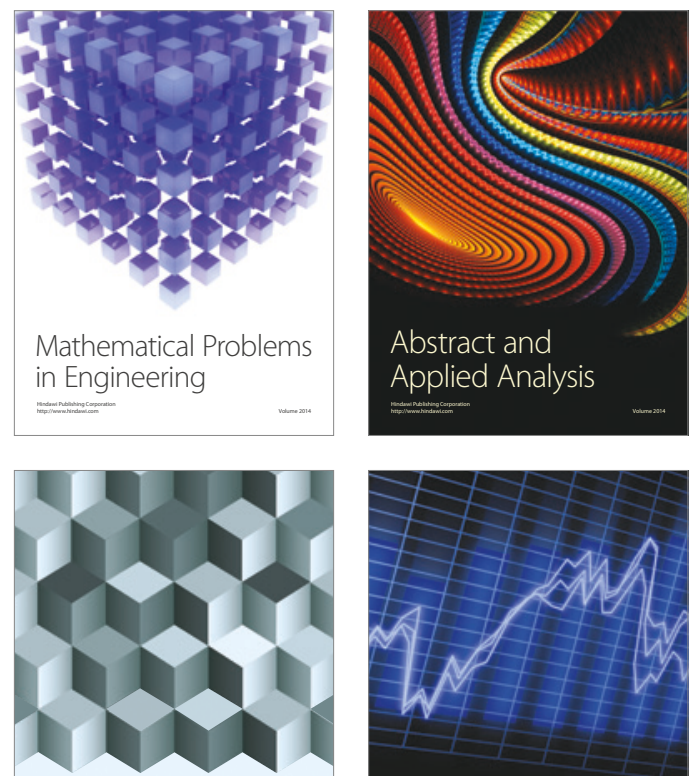

Journal of

Function Spaces

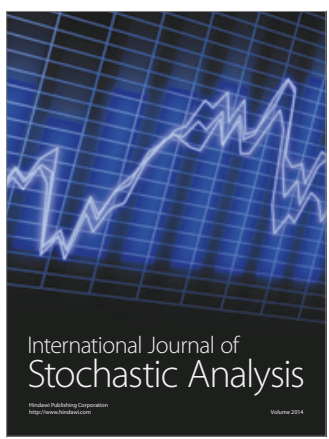

Probability and Statistics
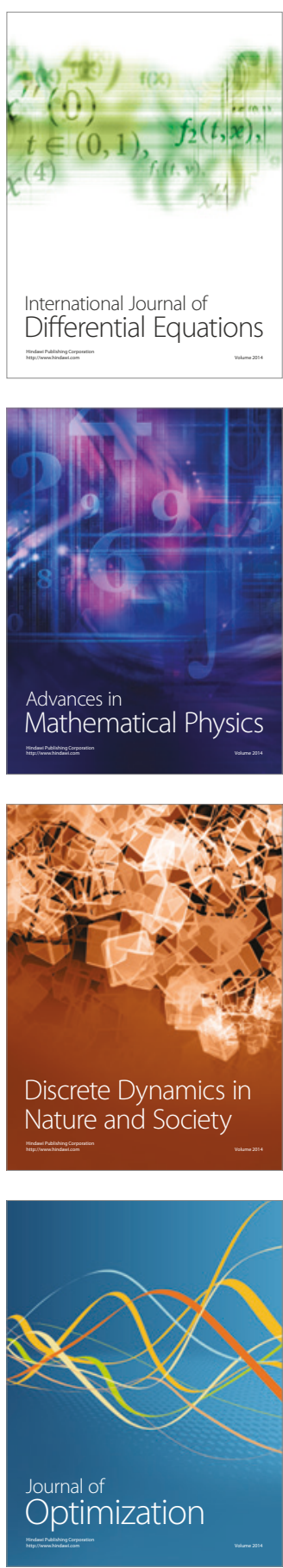